Short Communication

\title{
Comment on the paper "The optical properties of quantum dots in anisotropic media” by Singh et al., J. Mol. Liq. 241 (2017) 1009-1012
}

\section{Joy Sankar Roy}

Institute of Chemistry, São Paulo State University (UNESP), Araraquara, SP 14800-060, Brazil

\section{A R T I C L E I N F O}

\section{Article history:}

Received 4 February 2018

Accepted 21 April 2018

Available online 25 April 2018

\section{A B S T R A C T}

The present comment concerns some doubtful results reported by Singh et al. [1].

(c) 2018 Elsevier B.V. All rights reserved.
In results and discussion section of ref. [1], authors mentioned that "no absorption peak was observed for pure chloroform which makes it an appropriate solvent to be used as reference medium (Fig. 1)". In Fig. 1 of ref. [1], we can see that absorption spectrum of chloroform was not recorded properly. The absorption peak is saturated between $350 \mathrm{~nm}$ and $200 \mathrm{~nm}$. This is because of cut off intensity of the instrument i.e. that instrument can record data within the specified intensity. The authors should keep in mind that often an absorption peak is observed in chloroform around $280 \mathrm{~nm}$ due charge transfer (CT) band of oxygen containing chloroform [2]. Interestingly, authors also observed an absorption peak at $270 \mathrm{~nm}$ for CdSe QDs dispersed in chloroform and described that "an absorption peak has been observed at $270 \mathrm{~nm}$ for QDs dispersed sample 1 ". The most important point is that the band gap of bulk CdSe is $716 \mathrm{~nm}$ and it is very much difficult to achieve at $270 \mathrm{~nm}$ by reducing size [3,4]. Murray et al. [3] observed the band gap at $410 \mathrm{~nm}$ for $1.2 \mathrm{~nm}$ CdSe nanocrystals and Kongkanand et al. [5] reported this value as $505 \mathrm{~nm}$ for $2.3 \mathrm{~nm}$ CdSe quantum dots. Authors also did not provide electron microscopy image of CdSe and did not mention the size of the prepared CdSe QDs.

In Fig. 2, authors described that they observed absorption peak at about $440 \mathrm{~nm}$ for CdSe QDs dispersed in nematic liquid crystals and the red shift in absorption peak is due to presence of nematic liquid crystals. It is true that the absorption as well as emission band of the nanocrystals can be red shifted by changing surrounding medium with higher refractive index [6-8], but it is very difficult to shift absorption peak by $170 \mathrm{~nm}$. Authors also did not perform any direct measurement of refractive index of the samples.

In results and discussion section, the authors explained the cause of red shift in absorption band in following way:
“However absorption spectra of NLC-QDs composites (sample 3 ) show the reds shift in absorption peak. It is due to dielectric divergence between QDs and surrounding host anisotropic medium...."

According to authors' statement red shift in absorption peak is due to change of surrounding medium. But, in Fig. 8, authors described that the optical band gap of CdSe QDs is decreased due to enhancement of QDs size in presence of nematic liquid crystals. So, authors should not provide this schematic diagram and also should not explain their observed results in this way. This is totally optical phenomena and the red shift in absorption band of the CdSe QDs is due to higher refractive index of the surrounding medium.

\section{Acknowledgement}

The author acknowledges FAPESP (São Paulo Research Foundation, Brazil) for providing postdoctoral research fellowship (File no. 2017/ 16826-6).

\section{References}

[1] U.B. Singh, D. Singh, S. Kumar, R. Dhar, M.B. Pandey, J. Mol. Liq. 241 (2017) 1009.

[2] I. Iwakura, A. Yabushita, T. Kobayashi, J. Am. Chem. Soc. 131 (2009) 688.

[3] C.B. Murray, D.J. Noms, M.G. Bawendi, J. Am. Chem. Soc. 115 (1993) 8706.

[4] J.S. Roy, J. Mol. Liq. 243 (2017) 714.

[5] A. Kongkanand, K. Tvrdy, K. Takechi, M. Kuno, P.V. Kamat, J. Am. Chem. Soc. 130 (2008) 4007.

[6] C.N.R. Rao, S. Singh, V.P. Senthilnathan, Chem. Soc. Rev. 5 (1976) 297.

[7] J.S. Roy, T. Pal Majumder, Indian J. Phys. 89 (2015) 485.

[8] D. Haranath, S. Sahai, P. Joshi, Appl. Phys. Lett. 92 (2008) 233113. 